\title{
The Mediating Role of Self-Compassion in the Relationship Between Anxiety and Procrastination
}

\author{
Zahra Salehzadeh Einabad, ${ }^{1,}$ Golnaz Dorban, ${ }^{2}$ and Mohammadreza Nainian ${ }^{3}$ \\ ${ }^{1}$ Department of Clinical Psychology, Faculty of Humanities, Shahed University, Tehran, IR Iran \\ ${ }^{2}$ Department of Counseling Department, Faculty of Psychology, Islamic Azad University, Roodehen Unit, Tehran, IR Iran \\ ${ }^{3}$ Assistant Professor of Clinical psychology, Department of Clinical Psychology, Faculty of Humanities, Shahed University, Tehran, IR Iran \\ "Corresponding author: Zahra Salehzadeh Einabad, Department of Clinical Psychology, Faculty of Humanities, Shahed University, Tehran, IR Iran. E-mail: \\ z_salehzade@yahoo.com
}

Received 2017 April 18; Revised 2017 June 24; Accepted 2017 August 09.

\begin{abstract}
Background: Procrastination is common among students. There are inconsistent evidence indicating the relationship between anxiety and procrastination. Similarly, underlying mechanisms of this relationship is not fully understood. One of these mechanisms may be self-compassion that may counteracts the negative effects of anxiety and procrastination. Hence, this research is aimed at investigating the mediating role of self-compassion in the relationship between anxiety and procrastination.

Methods: This cross-sectional study was conducted in Shahed University. Subjects were selected from different faculties through cluster sampling method. Since a minimum sample size of 200 is necessary for Structural Equation Models, we distributed 300 questionnaires, but 210 questionnaires were appropriate to analysis. Students were asked to answer to tests, including anxiety, selfcompassion, and procrastination scale.

Results: Anxiety is correlated with procrastination and all subscales of self-compassion. Three components of self-compassion, including self-judgment $(\mathrm{r}=0.305, \mathrm{P}<0.001)$, isolation $(\mathrm{r}=0.225, \mathrm{P}=0.001)$, and over-identification $(\mathrm{r}=0.288, \mathrm{P}<0.001)$ have significant correlation with procrastination. Results of calculation in AMOS showed self-judgment and over-identification explain the relationship between self-compassion and procrastination, and they are full mediators of the relationship between anxiety and procrastination $(\mathrm{r}=0.236 ; \mathrm{P}=0.008 ; 95 \% \mathrm{CI}(0.069,0.453)$.

Conclusions: Results are consistent with the researches and theory. There are anxiety provoking factors among students correlated with the academic performance and getting accepted by peers, leading to self-judgment and over identification that are related to negative results such as procrastination.
\end{abstract}

Keywords: Procrastination, Self-Compassion, Anxiety, Self-Judgment, Over-identification

\section{Background}

Procrastination is considered as the tendency to avoid mandatory duties or tasks. Some studies reported between $75 \%$ - $95 \%$ of the students procrastinate [1]. Procrastination is correlated with low self-rated health [2]. A meta analysis showed procrastination was related to academic performance [3], well-being, and anxiety [4-6] because some individuals procrastinate to avoid a variety of aversive experiences such as fear, anxiety, and self-evaluative, anxietyprovoking thoughts. Support for this notion comes from a series of studies suggesting that procrastination may serve as an emotion regulatory function [7]. Students who pursue fun activities in order to increase their mood experience a paradoxical rise in distress [8]. Not only is the academic procrastination correlated with depression and anxiety, but also procrastination is conceptualized as a variable that affects the academic and social lives of the individuals in a negative way [9]. An experimental study [10] indicated subjects with a high-anxiety state were more likely to procrastinate. Academic procrastination was negatively related to academic performance satisfaction [11]. Anxiety underlies the links between chronic procrastination and health [12], and people with high anxiety are more likely to procrastinate than people with low anxiety [13]. However, results are inconsistent. While some studies show there is a significant relationship between procrastination and anxiety [3, 13-15] some findings do not confirm this relationship $[16,17]$. Similarly, some studies revealed the role of anxiety in procrastination is trivial $[18,19]$.

Researchers [20] focus on the main role of people' reactions in attenuating or exacerbating the anxiety response. Adaptive coping reactions such as self-compassion help successfully delete or decrease the stressor. Although selfcompassion is correlated with anxiety [15], its role in the relationship between anxiety and procrastination has not been widely investigated. Self-compassion is defined as being aware of one's own suffering, offering kindness towards oneself, taking a non-judgmental understanding to- 
wards one's failures, and framing one's own experience in light of the common human experience [21]. A research reported self-compassion was correlated with emotional health and was negatively associated with thought suppression, anxiety, self-criticism, depression [21]. Evaluating oneself in an critical and unkind way can explain the fact that procrastination plays a significant role in trait anxietywhich refers to a person's general tendency to become anxious [22].

Hence, it is not clear if anxiety is correlated with procrastination. Similarly, underlying mechanism in this relationship is not fully known. To date the role of components of self-compassion in explaining the anxiety correlated with procrastination has not been investigated in Iran, contributing to lack of designing the treatment protocol. Since psychological variables such as self-compassion [23] are totally different in Western and Eastern cultures, further investigation is necessary. So, we hypothesized there is a significant relationship between anxiety, procrastination and self-compassion, and components of selfcompassion mediate the relationship between anxiety and procrastination.

\section{Methods}

This cross-sectional study was conducted in Shahed University in 2016. Subjects were selected from different faculties, including, faculty of humanities, engineering, basic sciences, medicine, dentistry, and nursing faculties through cluster sampling method. Researchers have indicated a minimum sample size of 200 is necessary for structural equation models [24]. Hence, we distributed 300 questionnaires, but 210 questionnaires were appropriate to analysis. The subjects completed tests, including procrastination, self-compassion, and anxiety scales. Informed consent was obtained from all subjects.

\subsection{Trait Anxiety Inventory (TAI):}

This instrument was developed by Spielberger, Gorsuch, and Lushene (1970), and has 20 items [25]. Internal consistency coefficients for high school students were 0.86 [25]. To optimize content validity, most items were selected from other anxiety measures on the basis of strong associations with the Taylor manifest anxiety scale [26] and Cattell and Scheier's anxiety scale questionnaire [27]; overall correlations between the STAI and these 2 measures were 0.73 and 0.85 , respectively. An Iranian (Farsi) version of TAI was validated with a 0.90 Cronbach's alpha coefficients for trait anxiety 0.90 and a re-test reliability coefficient of .68 for the trait anxiety scale [28]. Validity of the test was confirmed with a significant correlation with Kattell anxiety questionnaire $(r=0.71)$.

\subsection{Self-Compassion Scale Short Form (SCS-SF):}

SCS-SF [29] has been developed by Raes et.al. (2011). SCSSF has 12 items. Researchers showed a high correlation between its long and short versions [29]. In a study, the test-retest reliability coefficient of this scale was obtained as 0.89 [30]. Moreover, factor analysis showed six factors for this scale, including common humanity, isolation, Over-identification, self-judgment, self-Kindness, Mindfulness. A study in Iran showed the internal consistency of this scale was 0.73 . Additionally, validity of this scale was confirmed using Kentucky inventory of mindfulness skills (KIMS) and the acceptance and act inventory-second edition (AAQ-II) $(\mathrm{r}=0.43, \mathrm{P} \leq 0.001$ and $\mathrm{r}=0.63, \mathrm{P} \leq 0.001$ respectively) [31].

\subsection{Procrastination Assessment Scale-Student (PASS)}

The PASS was developed by Solomon and Rothblum (1984) [4]. It has 18 items. Researchers reported alpha coefficient of 0.77 and showed that it has 3 factors [32]. The validity of the PASS was confirmed during the early development of the scale [4]. An Iranian study showed the reliability of the test was 0.78 . The predictive validity of the procrastination scale was confirmed by the negative correlation ( $r=-0.13$ ) between the scores of procrastination and the students' average score. Noteworthy, the factor analysis showed there are four factors [33].

Data were analyzed in SPSS-23 (for calculating descriptive results and Pearson correlation), and AMOS. Since structural equation modeling (SEM) provides a more appropriate inference framework for mediation analyses [34], we used AMOS to analyze the mediating role of selfcompassion in the relationship between procrastination and anxiety. In order to calculate the significance of the indirect effect we used bootstrapping with 2000 sampling in the $95 \%$ confidence interval.

\section{Results}

88 male students and 122 female students participated in this study, including 79 students from faculty of humanities (38 percent), 43 students from engineering faculty (20.5 percent), 31 students from basic sciences faculty (14.9 percent), 27 students from medicine faculty (13 percent), 15 students from dentistry faculty (7.2 percent), 15 (7.1\%) students from nursing faculty. The mean (standard deviation) age of the subjects was 20.54 (2.008) years. Table 1 represents the descriptive findings of variables.

Table 1 shows Kurtosis and Skewness lie within the acceptable range for normal distribution of data. Hair [35] argued data is considered to be normal if Skewness is between -2 to +2 and Kurtosis is between -7 to +7 . 
Table 1. Descriptive Results

\begin{tabular}{|c|c|c|c|c|c|c|}
\hline Variable & Mean & Std. Deviation & Maximum & Minimum & Kurtosis & Skewness \\
\hline Total procrastination & 55.6413 & 8.94489 & 85.00 & 32.00 & 0.136 & -0.036 \\
\hline Common humanity & 5.9505 & 1.59073 & 10.00 & 2.00 & 0.116 & 0.211 \\
\hline Isolation & 5.8503 & 1.86775 & 10.00 & 2.00 & -0.506 & 0.152 \\
\hline Over-identification & 6.0312 & 1.76673 & 10.00 & 2.00 & 0.006 & 0.001 \\
\hline Self-kindness & 6.4119 & 1.49446 & 10.00 & 2.00 & 0.072 & -0.139 \\
\hline Mindfulness & 6.7512 & 1.72323 & 10.00 & 2.00 & 0.036 & -0.434 \\
\hline Anxiety & 2.0146 & 0.47614 & 3.37 & 1.00 & 0.066 & 0.430 \\
\hline
\end{tabular}

Table 2 shows the correlation coefficients among predictive variables (anxiety), mediating variable (subscales and total score of self-compassion), as well as dependent variable (procrastination).

As Table 2 shows, anxiety has a significant relationship with procrastination and all subscales and total score of self-compassion $(\mathrm{P}<0.05)$. With the exception of common humanity, self-kindness, and mindfulness, other subscales had a significant relationship with procrastination $(\mathrm{P}<0.05)$.

In addition, due to the lack of a significant relationship with procrastination all dimensions of self compassionate scale cannot play a significant role in mediating the effects of anxiety on procrastination. Hence, first, in order to obtain a more exact estimation of the optimal combination of self-compassion's subscales in predicting procrastination relationship between dimensions of selfcompassion scale with procrastination was calculated after controlling the relationship among dimensions of selfcompassion scale. Figure 1 shows the output of these calculations.

As Figure 2 shows, after controlling the overlap among 6 subscales of Self-Compassion, only 2 components including self-judgment $(\mathrm{r}=0.22, \mathrm{P}=0.004)$ and overidentification ( $\mathrm{r}=0.17, \mathrm{P}=0.044)$ have a significant unique relationship with procrastination. Additionally, these two subscales have a significant relationship with each other ( $r=0.54, P>0.001)$. Since first model was a saturated model $(\mathrm{DF}=0)$, no fitness indices were calculated. In the next step, the mediating role of self-compassion subscales including self-judgment and over-identification in the relationship between procrastination and anxiety were calculated. In order to calculate the significance of the indirect effects, the model was conducted using bootstrapping method (with 2000 sampling). Figure 3 shows the output related to standard coefficients of the model.

Figure 3 shows anxiety has a significant and positive effect on latent variable derived from two components of self-judgment and over-identification $(\mathrm{r}=-0.66, \mathrm{P}<0.001)$. The effects of latent variable on procrastination was positive and significant $(\mathrm{r}=0.36, \mathrm{P}=0.003)$. Similarly, the direct effects of anxiety on procrastination was statistically insignificant $(\mathrm{r}=0.07, \mathrm{P}=0.503)$. Table 3 shows the results of bootstrapping in order to calculation of significance of the indirect effects in model 2.

As Table 3 shows the indirect effects of anxiety on procrastination was significant: 95\% CI (0.069, 0.453); P $=0.008 ; r=0.236$. Hence, self-compassion via its two subscales including self-judgment and over-identification plays a mediating role in the relationship between anxiety and procrastination. Since Figure 3 showed direct effect of anxiety on procrastination was insignificant, it can be concluded self-judgment and over-identification were full mediators of the relationship between anxiety and procrastination.

\section{Discussion}

This research showed there is a significant relationship between anxiety and procrastination. This result is consistent with earlier findings $[3,4,14,15]$, and can be explained according to an appraisal-anxiety-avoidance (AAA) model. Main cognitive theories of stress and coping [36] suggest if people perceive a circumstances to be threatening and their abilities and resources inadequate to deal with that threat, they are likely to react with stress. In fact, they may manifest anxiety and try to run away from that situation. Similarly, there is a significant relationship between self-compassion and procrastination and anxiety which is consistent with the literature [15]. People with higher levels of self-compassion adopt constructive coping strategies in the face of academic failure [37]. Self-compassion can increase self-regulation via decreasing negative states and negative self-evaluations like self-blame which may 
Table 2. Correlation Coefficient Matrix $(\mathrm{N}=210)$

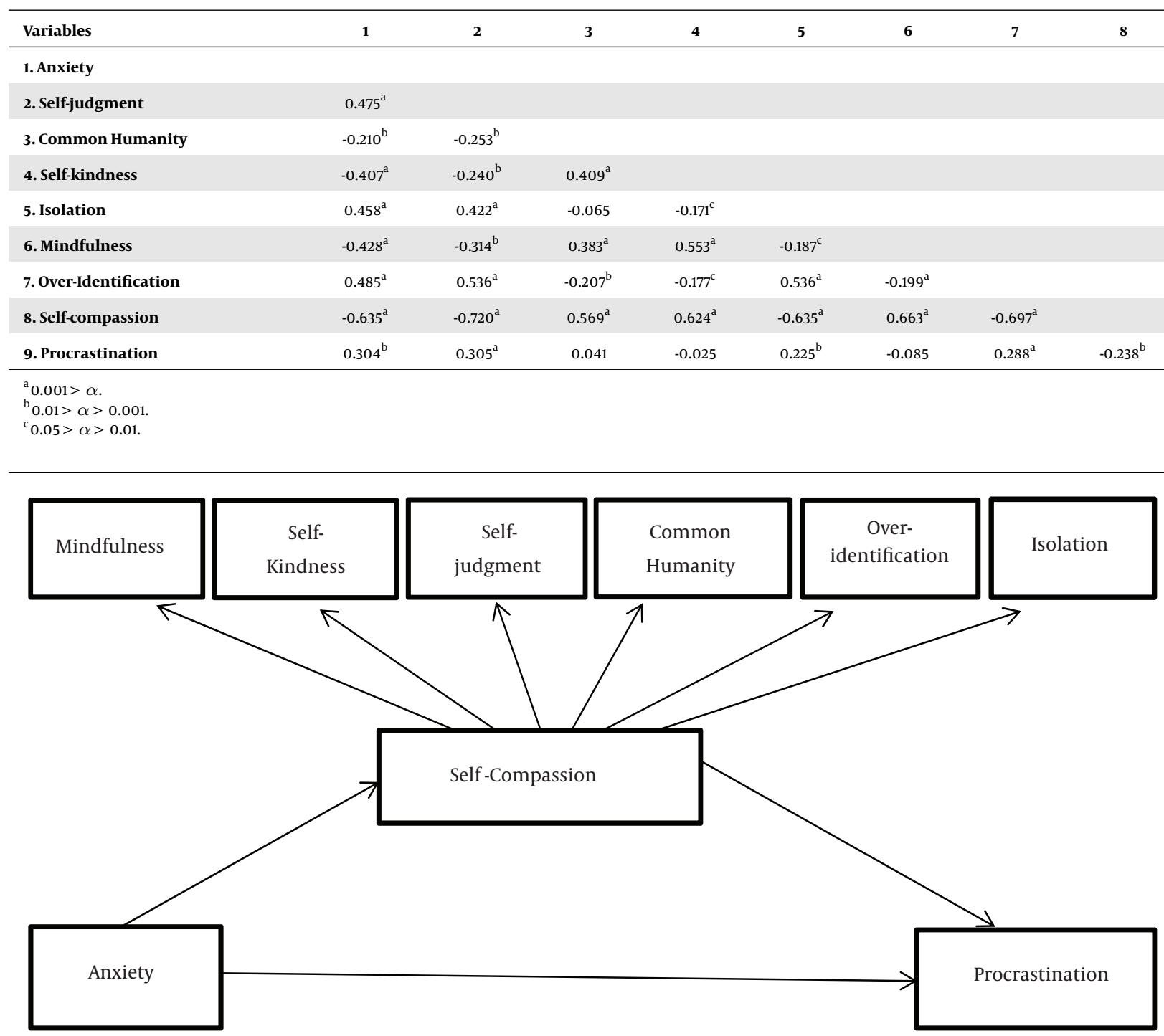

Figure 1. Conceptual Model

Table 3. The Results of Bootstrapping in Order to Calculation of Significance of the Indirect Effects in the Relationship Between Anxiety and Procrastination ${ }^{\mathrm{a}}$

\begin{tabular}{lcccc}
\hline Indirect Paths & Boot SE & Boot LLCI & Boot ULCI & PValue \\
\hline Anxiety $\rightarrow$ SCS $\rightarrow$ over identification & 0.070 & 0.318 & 0.600 \\
Anxiety $\rightarrow$ SCS $\rightarrow$ self-judgment & 0.065 & 0.347 & 0.482 & 0.599 \\
Anxiety $\rightarrow$ SCS $\rightarrow$ procrastination & 0.098 & 0.069 & 0.453 \\
\hline
\end{tabular}

${ }^{\text {a } S c s: ~ l a t e n t ~ v a r i a b l e ~ d e r i v e d ~ f r o m ~ t w o ~ c o m p o n e n t s ~ o f ~ s e l f-j u d g m e n t ~ a n d ~ o v e r ~ i d e n t i f i c a t i o n ; ~ b o o t s t r a p p i n g ~ w i t h ~} 2000$ sampling, $95 \%$ confidence interval.

disturb well-being and adaptive regulation [38]. Procrastination is considered as a form of self-regulation failure which is correlated with poor well-being [39], self-blame [38], and negative self-evaluations [13]. It is feasible a lack of 
Figure 2. Output of AMOS for the Optimal Combination of Self-Compassion's Subscale in Predicting Procrastination

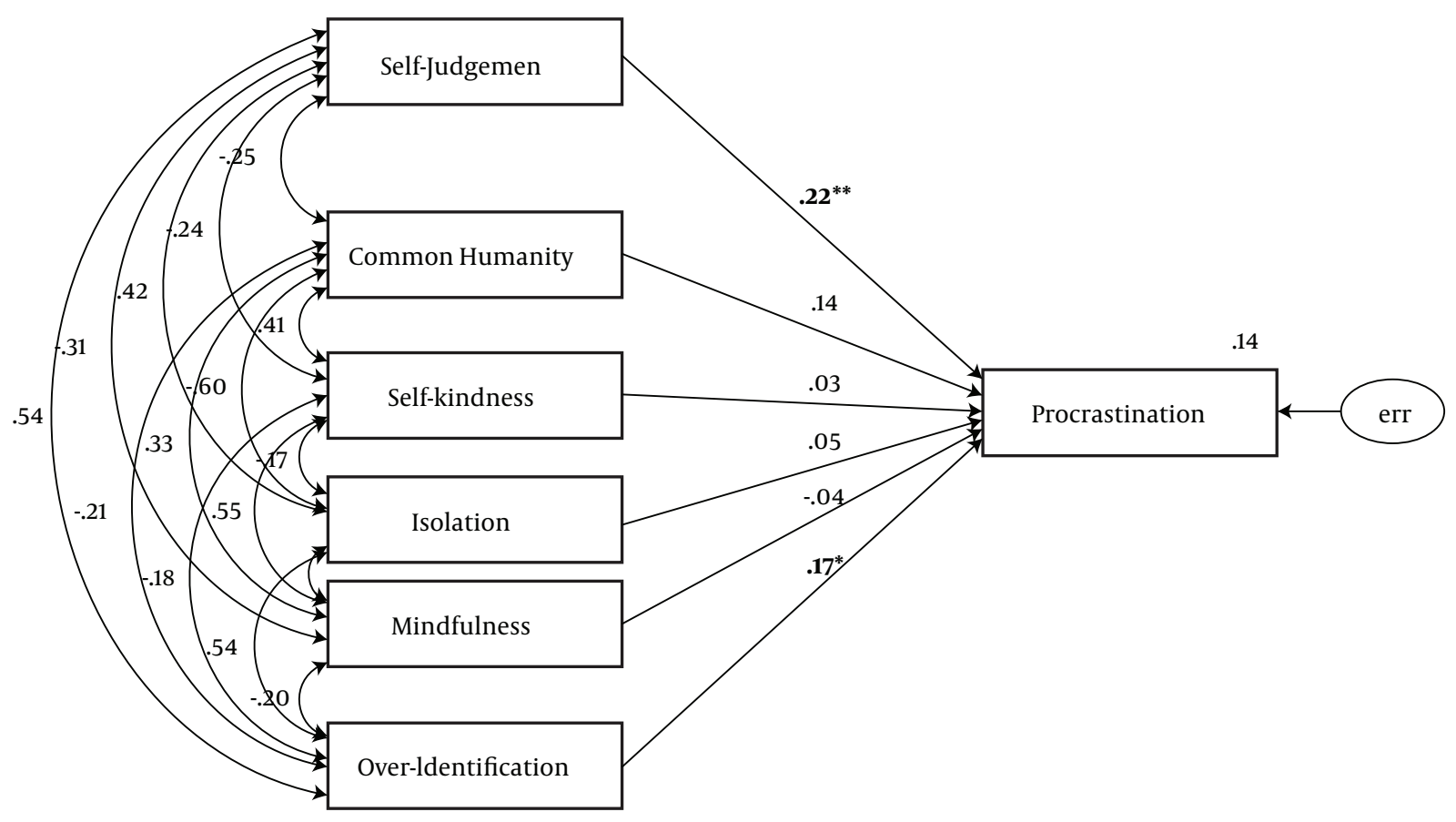

${ }^{* *}, 0.01>\alpha>0.001 ;{ }^{*}, 0.05>\alpha>0.01$.

Figure 3. The Mediating Role of Self-Compassion in the Relationship Between Anxiety and Procrastination

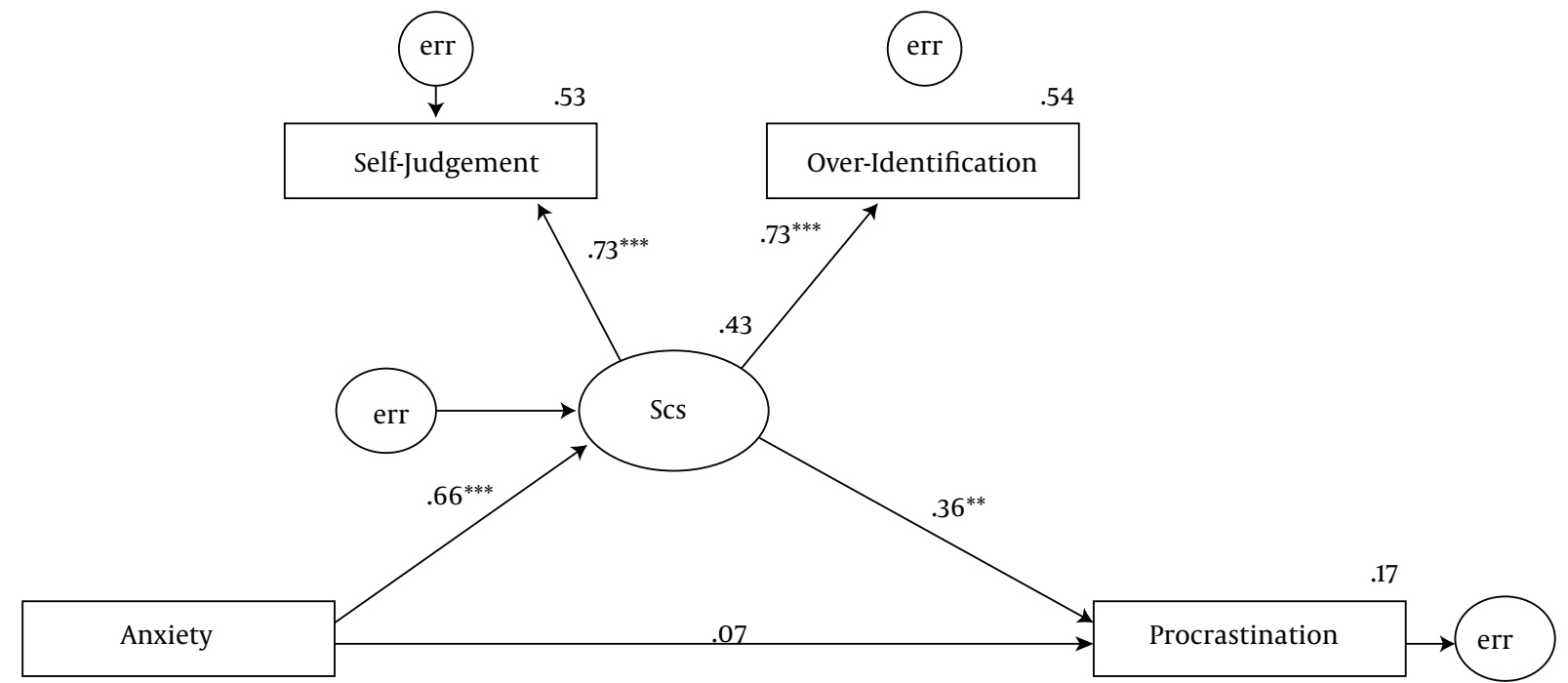

***, $0.001>\alpha ; * *, 0.01>\alpha>0.001$. Scs: latent variable derived from two components of self-judgment and over identification. Fitness indices: Chi-square/df $=0.119 ; \mathrm{P}=0.730$; $\mathrm{SRMR}=0.004 ; \mathrm{GFI}=1.000 ; \mathrm{AGFI}=0.997 ; \mathrm{NFI}=0.999 ; \mathrm{RFI}=0.996 ; \mathrm{IFI}=1.005 ; \mathrm{TLI}=1.031 ; \mathrm{CFI}=1.000 ; \mathrm{RMSEA}<0.001 ; \mathrm{PCLOSE}=0.790$.

self-compassion may lead to exacerbation of the procrastination [40]. Theory of meta-cognitive awareness [41] suggests lack of self-compassion to oneself after procrastinat- ing leads to self-blame and over-identification with negative states. These negative self-evaluations can increase procrastination. Research on the correlation between low 
levels of self-compassion and fear of failure [37] suggests there is a possible multi-directional relationship between procrastination and self-compassion so that fear of failure is considered as a reason for procrastination [3].

Researches show self-compassion provides people with the chance to recognize their part in negative events without becoming engaged in the ruminative procrastinator cognitions and negative emotions [40]. Self-compassion can have a substantial role in adaptive self-regulation through decreasing the negative emotional states and self-blame [42]. It should be noted Self-compassion is associated with the use of positive coping strategies such as cognitive restructuring which may help decrease anxiety [42]. This research showed self-judgment and over-identification mediate the relationship between anxiety and procrastination. However, a western study showed self-compassion is the mediator in the relationship between anxiety and procrastination [15]. As far as we know, this result was unique to this study. This result can be explained from some point of view. Firstly, a study showed procrastination had correlation with stress and self-blame [43]. This study indicated procrastination was correlated with self-blame for not engaging in the health-related behaviours and performances. It was also revealed self-blame could explain the relationship between stress and procrastination. People with habitual procrastination are likely to engage in rumination about previous procrastination behaviors since they can not engage in instrumental performances to move them closer to their goals [40]. Gradually, these constant negative self-evaluations can lead to a significant increase of tendency towards self-criticism, self-blame. In line with this, researchers [44] showed a generalized tendency to be critical and unkind to oneself in people with procrastination.

Secondly, self-compassion, in the face of failure, facilitates the learning process through freeing people from the harmful consequences of over-identification, isolation, and self-criticism. So, it is not surprising that over-identification and self-judgment mediated the relationship between anxiety and procrastination. Selfcompassion is a unique construct for the youth because they face with social comparison and they evaluate themselves [42]. They experience more stressful factors which are related to academic performance and getting accepted by peers. These factors result in over-identification and self-judgment which are correlated with anxiety [42] and can lead to procrastination.

Last but not least, researchers [44] showed Taiwanese participants scored higher than the American participants in three negative SCS subscales of self-judgment, over-identification, and isolation. The researchers found the Taiwanese parents explicitly or implicitly use shamebased strategies to socialize their children [23]. The researchers concluded the Eastern societies emphasize shame, judgment, and threatened isolation as means of self-improvement.

Noteworthy, this study has some limitations. First, only student sample was selected. So, the generalization of the findings are nor possible. Secondly, cross-sectional studies do not reveal casual relationships. So, it is suggested future studies target other populations and longitudinal studies be conducted. On the other hand according to literature, the role of variables such as mindfulness and acceptance [14] should be investigated in the link between anxiety and procrastination since designing a protocol requires understanding the other factors.

In conclusion, people with procrastination treat themselves with self judgment rather than self-compassion, contributing to the anxiety they experience. Therefore, encouragement of self-compassion in students can be highly constructive. These kinds of interventions can be a useful treatment, since they lead to remediate harmful selfattitudes in a more constructive way. The encouragement of self-compassion on the part of teachers and an emphasis on mastery rather than performance goals can be more beneficial.

\section{Acknowledgments}

All procedures performed in studies involving human participants were in accordance with the ethical standards of the institutional and /or national research committee and with the 1964 Helsinki declaration and its later amendments or comparable ethical standards.

\section{Footnotes}

Authors' Contribution: All authors had equal role in design, work, statistical analysis and manuscript writing.

Conflict of Interests: The authors declare no conflict of interest.

\section{Funding/Support: Non}

\section{References}

1. Potts TJ. Predicting procrastination on academic tasks with selfreport personality measures. Hofstra University; 1987.

2. Sirois FM, Tosti N. Lost in the moment? An investigation of procrastination, mindfulness, and well-being. J Ration Emot Cogn Behav Ther. 2012;30(4):237-48. doi: 10.1007/s10942-012-0151-y.

3. Steel P. The nature of procrastination: a meta-analytic and theoretical review of quintessential self-regulatory failure. Psychol Bull. 2007;133(1):65-94. doi: 10.1037/0033-2909.133.1.65. [PubMed: 17201571]. 
4. Solomon LJ, Rothblum ED. Academic procrastination: Frequency and cognitive-behavioral correlates. J Couns Psychol. 1984;31(4):503-9. doi: 10.1037/0022-0167.31.4.503.

5. Fritzsche BA, Rapp Young B, Hickson KC. Individual differences in academic procrastination tendency and writing success. Pers Individ Dif. 2003;35(7):1549-57. doi: 10.1016/s0191-8869(02)00369-0.

6. Macher D, Paechter M, Papousek I, Ruggeri K. Statistics anxiety, trait anxiety, learning behavior, and academic performance. Eur J Psychol Educ. 2011;27(4):483-98. doi: 10.1007/s10212-011-0090-5.

7. Sirois FM, Pychyl T. Procrastination and the priority of short-term mood regulation: Consequences for future self. Soc Personal Psychol Compass. 2013;7(2):115-27. doi: 10.1111/spc3.12011.

8. Patry DA, Blanchard CM, Mask L. Measuring university students' regulatory leisure coping styles: Planned breathers or avoidance? Leis Sci. 2007;29(3):247-65. doi: 10.1080/01490400701257963.

9. Beutel ME, Klein EM, Aufenanger S, Brahler E, Dreier M, Muller KW, et al. Procrastination, Distress and Life Satisfaction across the Age Range - A German Representative Community Study. PLoS One. 2016;11(2):e0148054. doi: 10.1371/journal.pone.0148054. [PubMed 26871572]

10. Xu P, González-Vallejo C, Xiong ZH. State anxiety reduces procrastinating behavior. Motiv Emot. 2016;40:625.

11. Balkis M, Duru E. Gender differences in the relationship between academic procrastination, satifaction with academic life and academic performance. Electron J Res Educ Psychol. 2017;15(1):105-25.

12. Sirois FM, Melia-Gordon ML, Pychyl TA. "I'll look after my health, later": an investigation of procrastination and health. Pers Individ Dif. 2003;35(5):1167-84. doi: 10.1016/s0191-8869(02)00326-4.

13. Flett GL, Blankstein KR, Martin TR. In: Procrastination, and task avoidance: Theory, research, and treatment. Ferrari JR, J.H. Johnson JH, McCown WG, editors. New York: Plenum; 1995. pp. 13767.Procrastination, Negative Self-Evaluation, and Stress in Depression and Anxiety: A review and preliminary model.

14. Glick DM, Millstein DJ, Orsillo SM. A preliminary investigation of the role of psychological inflexibility in academic procrastination.J Contextual Behav Sci. 2014;3(2):81-8. doi:10.1016/j.jcbs.2014.04.002.

15. Sirois FM. Procrastination and stress: Exploring the role of self-compassion. Self Identity. 2013;13(2):128-45. doi: 10.1080/15298868.2013.763404.

16. Lay CH, Edwards JM, Parker JDA, Endler NS. An assessment of appraisal, anxiety, coping, and procrastination during an examination period. Eur J Pers. 1989;3(3):195-208. doi:10.1002/per.2410030305.

17. lay $\mathrm{CH}$. In: Procrastination and task avoidance: Theory, research and treatment. Ferrari JR, Johnson JL, McCown WG, editors. New York: Plenum;1995.p. 97-112.Trait procrastination, agitation, dejection, and self-discrepancy.

18. Johnson JL, Bloom AM. An analysis of the contribution of the five factors of personality to variance in academic procrastination. Pers Individ Dif. 1995;18(1):127-33. doi:10.1016/0191-8869(94)00109-6.

19. Schouwenburg HC, Lay CH. Trait procrastination and the Big-five factors of personality. Pers Individ Dif. 1995;18(4):481-90. doi:10.1016/01918869(94)00176-s

20. Tice DM, Baumeister RF. Longitudinal study of procrastination, performance, stress, and health: The costs and benefits of dawdling. Psychol Sci. 2016;8(6):454-8. doi: 10.1111/j.1467-9280.1997.tb00460.x.

21. Neff KD, Kirkpatrick KL, Rude SS. Self-compassion and adaptive psychological functioning. J Res Pers. 2007;41(1):139-54. doi 10.1016/j.jrp.2006.03.004.

22. Wilt J, Oehlberg K, Revelle W. Anxiety in personality. Pers Individ Dif. 2011;50(7):987-93. doi:10.1016/j.paid.2010.11.014.

23. Fung H, Chen ECH. Across time and beyond skin: Self and transgression in the everyday socialization of shame among taiwanese preschool children. Soc Dev. 2001;10(3):419-37. doi: 10.1111/14679507.00173.
24. Boomsma A. Nonconvergence, improper solutions, and starting values in lisrel maximum likelihood estimation. Psychometrika. 1985;50(2):229-42. doi: 10.1007/bfo2294248.

25. Spielberger C. Manual for the State-Trait Anxiety Inventory. Palo Alto, CA: Consulting Psychologists Press; 1983.

26. Taylor JA. A personality scale of manifest anxiety. I Abnorm Psychol. 1953;48(2):285-90. doi: 10.1037/h0056264. [PubMed: 13052352].

27. Cattell RB, Sheier IH. Handbook for the IPAT Anxiety Scale. 2nd ed. Champaign, IL: Institute for Personality and Ability Testing; 1963.

28. Panahi Reishahri M. Preliminary investigation of the validity $[\mathrm{U}+060 \mathrm{C}]$ reliability and normalization of the Spielberger test [In Persian]. Tehran, Iran: TarbiatModdares University; 1992.

29. Raes F, Pommier E, Neff KD, Van Gucht D. Construction and factorial validation of a short form of the Self-Compassion Scale. Clin Psychol Psychother. 2011;18(3):250-5. doi: 10.1002/cpp.702. [PubMed: 21584907].

30. Neff KD. The self-compassion scale is a valid and theoretically coherent measure of self-compassion. Mindfulness. 2015;7(1):264-74. doi: 10.1007/s12671-015-0479-3.

31. Salehzadeh Einabad Z. Psychometric features of self-compassionate short form. ;In press.

32. Yockey RD, Kralowec CJ. Confirmatory factor analysis of the procrastination assessment scale for students. SAGE Open. 2015;5(4):1-5. doi: $10.1177 / 2158244015611456$.

33. Mortazavi F, Mortazavi SS, Khosrorad R. Psychometric Properties of the Procrastination Assessment Scale-Student (PASS) in a Student Sample of Sabzevar University of Medical Sciences. Iran Red Crescent Med J. 2015;17(9):e28328. doi: 10.5812/ircmj.28328. [PubMed: 26473078].

34. Gunzler $\mathrm{D}$, Chen $\mathrm{T}$, Wu $\mathrm{P}$, Zhang $\mathrm{H}$. Introduction to mediation analysis with structural equation modeling. Shanghai Arch Psychiatry. 2013;25(6):390-4. doi: 10.3969/j.issn.1002-0829.2013.06.009. [PubMed: 24991183].

35. Hair JJF, Black JW, Babin BJ, Anderson ER. Multivariate Data Analysis. seventh ed. Edinburgh: Pearson Education Limited; 2010. pp.1-758.

36. Hobfoll SE. Conservation of resources. A new attempt at conceptualizing stress. Am Psychol. 1989;44(3):513-24. doi: 10.1037/0003066X.44.3.513. [PubMed: 2648906].

37. Neff KD, Hsieh YP, Dejitterat K. Self-compassion, achievement goals, and coping with academic failure. Self Identity. 2005;4(3):263-87. doi: $10.1080 / 13576500444000317$.

38. Sirois FM. "I'll look after my health, later": A replication and extension of the procrastination-health model with community-dwelling adults. Pers Individ Dif. 2007;43(1):15-26. doi: 10.1016/j.paid.2006.11.003.

39. Neff KD, McGehee P. Self-compassion and psychological resilience among adolescents and young adults. Self Identity. 2010;9(3):225-40. doi: $10.1080 / 15298860902979307$.

40. Stainton M, Lay CH, Flett GL. Trait procrastinators and behavior/traitspecific cognitions. J Soc Behav Pers. 2000;15(5):297-312.

41. Teasdale JD, Segal Z, Williams JMG. How does cognitive therapy prevent depressive relapse and why should attentional control (mindfulness) training help? Behav Res Ther. 1995;33(1):25-39. doi:10.1016/00057967(94)e0011-7.

42. McCown WG, Blake I, Keiser R. Content Analyses of the Beliefs of Academic Procrastinators. J Ration Emot Cogn Behav Ther. 2012;30(4):21322. doi: 10.1007/s10942-012-0148-6.

43. Sirois FM, Stout D. When knowing better doesn't mean doing better: Understanding the roles of procrastination and self-blame in the health and well-being of nurses. Paper presented at the 7th Biennial Conference on Procrastination. Amsterdam,The Netherelands.

44. Neff KD, Pisitsungkagarn K, Hsieh YP. Self-compassion and selfconstrual in the United States, Thailand, and Taiwan. J Cross Cult Psychol. 2008;39(3):267-85. doi:10.1177/0022022108314544. 